\title{
A computational study of the succinimide derivative surfactant
}

\author{
K. Kovalchuk ${ }^{1}$, M. Landman ${ }^{2}$, I. Masalova ${ }^{1}$ * \\ ${ }^{1}$ Material Science and Technology Group, Engineering Faculty, \\ Cape Peninsula University of Technology (CPUT), P.O. Box 8000, Cape Town, South Africa \\ ${ }^{2}$ University of Pretoria, Department of Chemistry, Pretoria, South Africa
}

\begin{abstract}
Density functional theory (DFT) of calculations was used to optimize the molecular structures of a succinimide surfactant at B3LYP/6-311 level. The interaction of the surfactant with water molecules was investigated. The hydration shell was formed in the form of $\mathrm{H}$ bonds between the hydrophilic group on the surfactant and water molecules. The binding energy of the system increases due to hydrogen bond formation with the water molecules.
\end{abstract}

Keywords: DFT, surfactants, hydrogen bonding, solvation

\section{GRAPHICAL ABSTRACT}

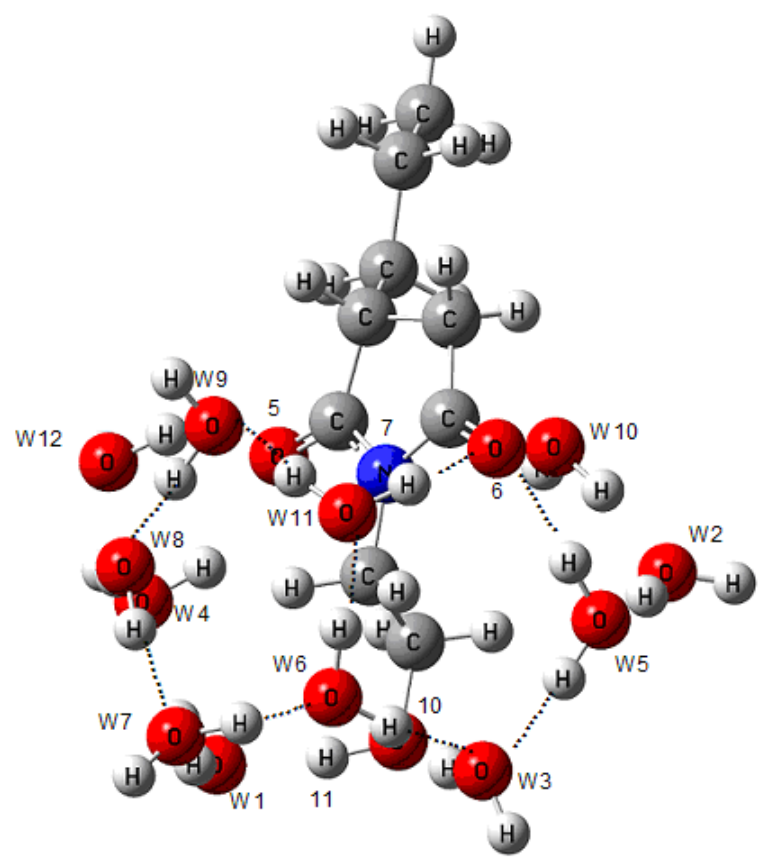

* Corresponding author: karinask@chemeng.ntnu.no Tel: +4773550325 


\section{INTRODUCTION}

Surfactant molecules are widely used for emulsion stabilization because of their ability to adsorb at the interface and reduce interfacial tension. This is due to their dual chemical nature namely the existence of hydrophilic and hydrophobic domains in one molecule [1,2]. It is known that the surfactant structure influences the interfacial [3-6] and bulk properties [3, 4] of a system and has an effect on emulsion stability [1, 3, 7-9]. Therefore, investigation of molecular properties of surfactant structure is an important aspect in understanding the factors that influence emulsion stability.

The orientation of the different surfactants at the interface is attributed to the different polar groups of the molecules and depends on the molecular interactions between the head groups of the surfactant and molecules of the aqueous phase $[1,10,11]$. The molecular interactions between surfactant and water molecules can be calculated with the use of computational modeling [12-14] which is known as a powerful tool to study complex interfacial systems [2]. Using this tool it is possible, at a molecular level, to extract information about the structural properties of the system which is not easy to obtain from physical experiments. Relatively few studies involving the application of quantum chemical methods to surfactant properties can be found in literature. Huibers et al. studied molecular dipole moments of anionic surfactants as a parameter in the prediction of the influence of molecular structure on critical micelle concentration and the charge distribution in ionic surfactants was investigated [15]. Dominguez focused on charge effects in surfactant monolayer mixtures at the water/oil interface $[10,16]$. Simulations of different surfactant systems showed that the location of the different surfactants at the interface is determined by the interaction and charge distribution of the molecules. A molecular modeling approach, including the design of surfactant structures based on their area and volume, was proposed by Villamagna and co-workers [3]. Little work has been reported on the molecular interactions between surfactants and especially between surfactants and solvent at the interface with density functional theory (DFT) due to the computational time required for systems with a large number of atoms in the molecule. However, computational studies of quaternary alkyl ammonium surfactants water clusters [13] and alkyl sulfate surfactant complex formation with water [12, 14] were performed with the use of DFT. 
In this article we report the results of investigating the surfactant structure and its interaction with water molecules in order to build the structure of a hydrated surfactant head group, and investigate the effect of solvent media on molecular structure and properties. This will allow for better understanding of surfactant adsorption at the interface and its structural arrangements.

\section{METHOD}

Density functional theory (DFT) calculations were performed with the hybrid B3LYP functional, a three-parameter functional developed by Becke, which uses the Lee-Yang-Parr correlation functional in its Gaussian 03 [17] implementation. In the DFT calculations the molecular structures were fully optimized using the B3LYP/6-311+G set. The calculations were performed in vacuo and also in aqueous medium. The following prominent quantum chemical parameters were obtained for the surfactant 1-(2-hydroethyl)pyrrolidine -2,5-dione derivative, (IMIDE). The head group structure of the surfactant is shown in Figure 1.

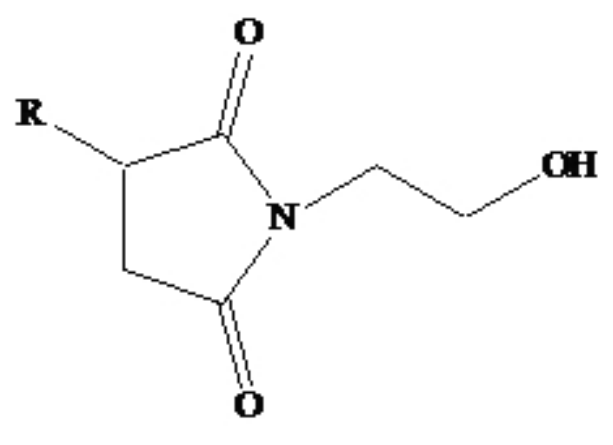

$$
\mathbf{R}=\text { allyl chain }
$$

Figure 1: Head group structure of IMIDE surfactant

\subsection{Atomic charges}

Electronic charges in the molecule are obviously responsible for electrostatic interactions. Mulliken population analysis is most commonly used for the calculation of the charge distribution in the molecule [18]. The atomic charges give a qualitative understanding of the 
structure and reactivity of molecule and they are used for the description of the molecular polarity of the molecules [19].

\subsection{Dipole moment}

The dipole moment is the measure of polarity of a polar covalent bond. It is defined as the product of charge on atoms and the distance between the two bonded atoms. For a complete molecule the total molecular dipole moment may be approximated as the vector sum of individual bond dipole moments [19].

\subsection{Energy}

The total energy of a system (molecule) is composed of the internal, potential, and kinetic energy [19]. The minimum value of the total energy functional is the ground state energy of a system.

Zero point energy corrections were performed as follows [13]:

$\mathrm{E}_{\mathrm{ZPE}}=\mathrm{E}_{\mathrm{TOTAL}}+\Delta \mathrm{ZPE}$

where $\mathrm{E}_{\mathrm{ZPE}}=$ zero point corrected energy $(\mathrm{kJ} / \mathrm{mol}) ; \mathrm{E}_{\mathrm{TOTAL}}=$ minimum total energy of system $(\mathrm{kJ} / \mathrm{mol}) ; \Delta \mathrm{ZPE}=$ zero point energy correction $(\mathrm{kJ} / \mathrm{mol})$.

The results discussed below are without the BSSE (basis set super position error) correction. The following reasons can be stated [12]: there is no definite definition for BSSE in DFT and BSSE is based on the theory of molecular orbitals; BSSE is calculated by ab-initio methods and is unimportant for stronger $\mathrm{H}$-bond systems and it is very complicated for multiple water molecules systems.

The binding energy $\mathrm{D}_{0}$ (ZPE corrected) was given as the difference between the total energy of the system and the sum of energy of the isolated molecule and individual $\mathrm{H}_{2} \mathrm{O}$ molecules. This supermolecular approach was used in literature reports for similar studies $[12,13,20]$.

$\mathrm{D}_{0}=-\Delta \mathrm{E}=\mathrm{E}_{\mathrm{MOLECULE}}+\mathrm{nE}_{\mathrm{H}_{2} \mathrm{O}}-\mathrm{E}_{\mathrm{MOLECULE}\left(\mathrm{H}_{2} \mathrm{O}\right) \mathrm{n},}$ 
where $\mathrm{D}_{0}=$ binding energy of a surfactant to water molecules $(\mathrm{kJ} / \mathrm{mol}) ; \mathrm{E}_{\mathrm{H}_{2} \mathrm{O}}=$ energy of water molecule $(\mathrm{kJ} / \mathrm{mol})$; $\mathrm{E}_{\mathrm{MOLECULE}\left(\mathrm{H}_{2} \mathrm{O}\right) \mathrm{n}}=$ energy of surfactant complex with $\mathrm{n}$ molecules of $\mathrm{H}_{2} \mathrm{O}(\mathrm{kJ} / \mathrm{mol})$.

Incremental binding energy $\Delta \mathrm{D}_{0}$ was calculated as [12]:

$\Delta \mathrm{D}_{0}=\mathrm{D}_{0}$ MOLeCUle(H2O)n $-\mathrm{D}_{0} \operatorname{MOLECULE}\left(\mathrm{H}_{2} \mathrm{O}\right) \mathrm{n}-1$,

where $\mathrm{D}_{0}$ MOLECULE( $\left.\mathrm{H}_{2} \mathrm{O}\right) \mathrm{n}=$ energy of surfactant complex with $\mathrm{n}$ molecules of water $(\mathrm{kJ} / \mathrm{mol})$; $\mathrm{D}_{0}$ MOLECULE(H2O)n-1 $=$ energy of surfactant complex with $\mathrm{n}-1$ molecules of water $(\mathrm{kJ} / \mathrm{mol})$.

\subsection{Solvation}

To determine the minimum energy and dipole moment of structures the solvation of molecules was performed. Solvation is associated with the interaction between the molecules of a solvent and the surfactant. The space occupied by the solute molecules dispersing the solvent molecules is said to be the solvent cavity. The energy required to push aside solvent molecules is known as the cavitation energy. This is thermodynamically balanced by the solvent-solute interaction [13].

The solvation parameters were obtained with the use of the IEFPCM (Integral Equation Formalism Polarizable Continuum Model). The PCM (Polarizable Continuum Model) model calculates the molecular free energy in solution $\left(\Delta \mathrm{G}_{\mathrm{sol}}, \mathrm{kJ} / \mathrm{mol}\right)$ which represents the interactions between the surfactant molecule and solvent as the sum over three terms [21, 22]:

$\Delta \mathrm{G}_{\mathrm{sol}}=\mathrm{G}_{\mathrm{el}}+\mathrm{G}_{\mathrm{dr}}+\mathrm{G}_{\mathrm{cav}}$,

where $\mathrm{G}_{\mathrm{el}}=$ electrostatic contribution to the free energy in solution $(\mathrm{kJ} / \mathrm{mol}) ; \mathrm{G}_{\mathrm{dr}}=$ dispersion-repulsion contributions to the free energy in solution $(\mathrm{kJ} / \mathrm{mol}) ; \mathrm{G}_{\mathrm{cav}}=$ cavitation energy, kJ/mol. 


\section{RESULTS AND DISCUSSIONS}

\subsection{Effect of tail length on the molecular energy and dipole moment}

In order to investigate the effect of surfactant tail length on the molecular structure and dipole moment of the molecule, carbon atoms were added to the molecule in a step-wise manner by insertion of $\mathrm{CH}_{2}$-groups in the alkyl chain, and optimized as described in section 2. The results are presented in Figure 2.

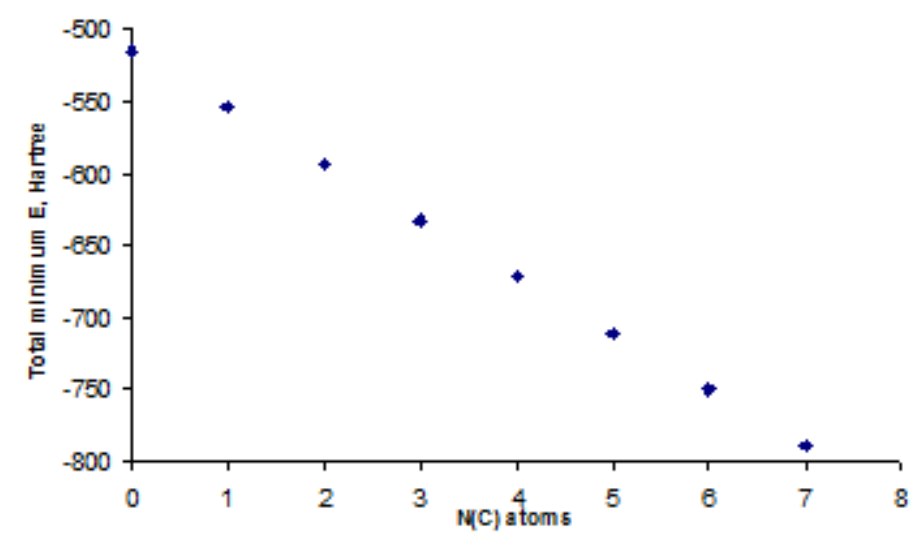

Figure 2: The effect of tail length on molecular energy of IMIDE surfactant

It is seen from Figure 2 that the total energy E (ZPE corrected) of the molecule changes linearly as the number of carbon atoms in the hydrocarbon chain increases. A similar result was found in literature $[12,13]$. The result indicates that stability of the molecular structure does not change with the number of carbon atoms [12]. The incremental total energy $(\Delta \mathrm{E})$ can be used to describe the effect of the additional carbon atom on the total energy of the molecule $(\mathrm{E})$. Figure 3 shows the relationship of the incremental total energy $(\Delta \mathrm{E})$ with increase of the number of carbon atoms in the tail group of surfactant.

As shown in Figure 3 there is a similar change in energy of the molecule (starting from the second carbon atom in the chain) with each carbon atom added to the surfactant molecule. This observation shows that subsequent extension of the alkyl carbon chain does not influence the stability of the molecule [12]. 


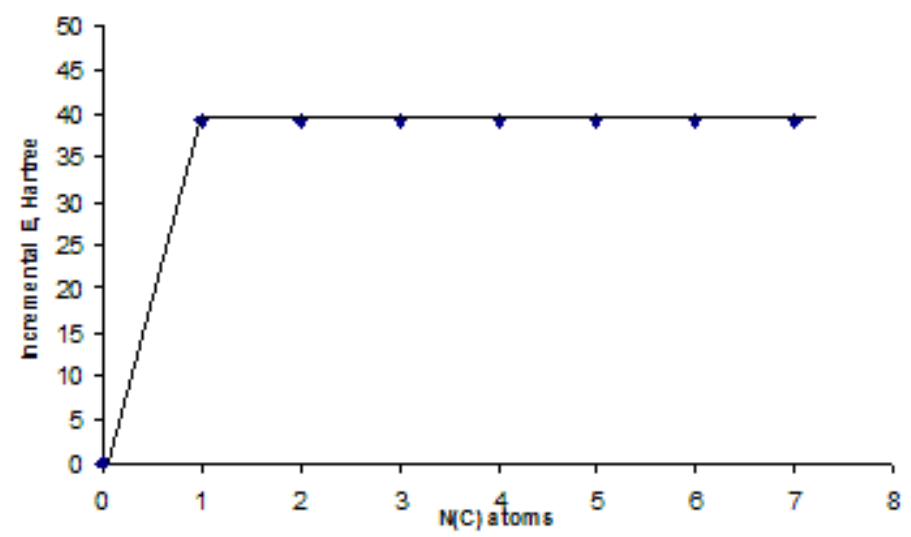

Figure 3: The incremental energy $(\Delta E)$ as a function of number of carbon atoms in surfactant hydrocarbon chain

The charge distribution in the surfactant molecule was also studied. NBO (Natural bond orbital) population analysis was performed in order to obtain natural charges. The results are summarized in Table 2, excluding the alkyl chain hydrogen atoms, as these did not vary significantly. Figure 4 presents the optimized structure of the IMIDE head group with a tail consisting of 7 carbon atoms.

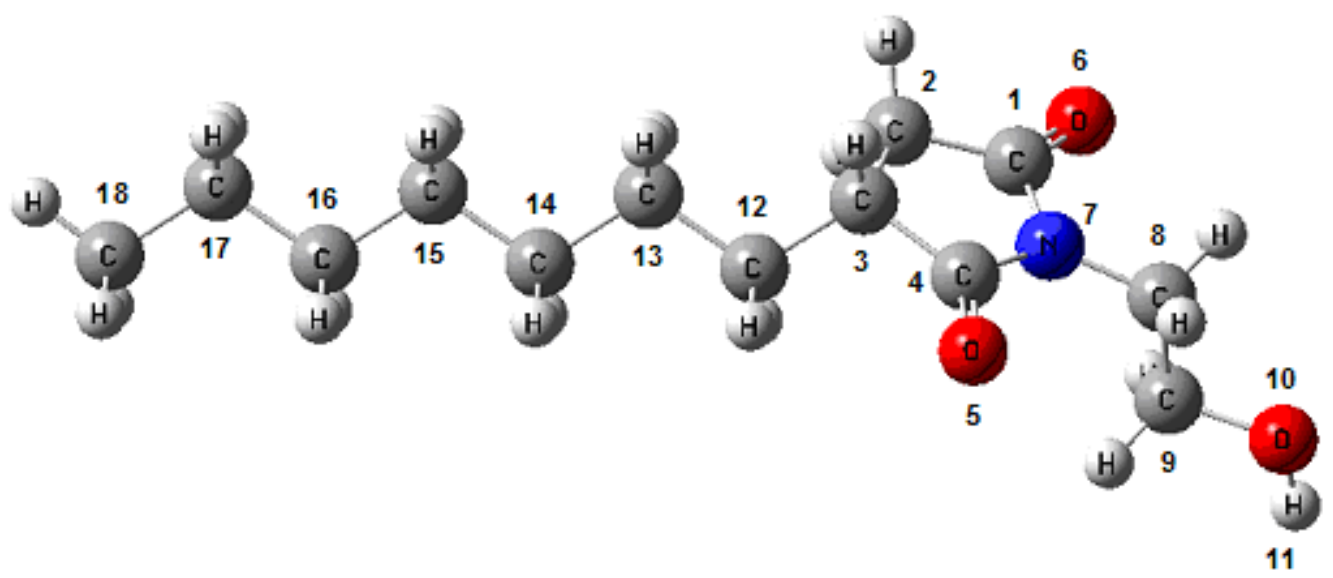

Figure 4 : IMIDE head group with 7 carbon atoms attached. 
The charge distribution in the head group is mostly unaffected by an increase in carbon atoms in the chain. The slight effect becomes even less with each subsequent addition of carbon atoms in the chain and no change in head group charge was observed after the third carbon atom was added. Therefore the surfactant head group structure with three carbons attached was used for further calculations.

Another point to stress is that not only the head group atoms are charged, but significant charges is observed on the atoms of the alkyl tail, specifically on the carbon atom of the terminating $-\mathrm{CH}_{3}$ group . The presence of a partial charge in the alkyl tail of surfactants was also shown in publication [15]. Presence of the charge in the chain may play an important role in interactions between the surfactant chains and affect the surfactant packing at the interface.

Table 1: Summary of atomic charges in IMIDE surfactant with different numbers of carbon atoms

\begin{tabular}{|c|c|c|c|c|c|c|c|c|}
\hline \multicolumn{9}{|c|}{ Number of carbon atoms } \\
\hline & 0 & 1 & 2 & 3 & 4 & 5 & 6 & 7 \\
\hline $\mathrm{C} 1$ & 0.679 & 0.682 & 0.683 & 0.683 & 0.683 & 0.683 & 0.683 & 0.683 \\
\hline $\mathrm{C} 2$ & -0.470 & -0.471 & -0.474 & -0.474 & -0.474 & -0.474 & -0.474 & -0.474 \\
\hline C3 & -0.470 & -0.281 & -0.287 & -0.283 & -0.282 & -0.282 & -0.282 & -0.282 \\
\hline $\mathrm{C} 4$ & 0.679 & 0.683 & 0.688 & 0.689 & 0.689 & 0.689 & 0.689 & 0.689 \\
\hline $\mathrm{O} 5$ & -0.570 & -0.570 & -0.571 & -0.571 & -0.571 & -0.571 & -0.571 & -0.572 \\
\hline O6 & -0.570 & -0.577 & -0.578 & -0.579 & -0.579 & -0.580 & -0.580 & -0.579 \\
\hline N7 & -0.483 & -0.481 & -0.481 & -0.481 & -0.481 & -0.481 & -0.481 & -0.481 \\
\hline $\mathrm{C} 8$ & -0.204 & -0.204 & -0.204 & -0.204 & -0.204 & -0.204 & -0.204 & -0.204 \\
\hline C9 & -0.026 & -0.025 & -0.025 & -0.025 & -0.025 & -0.025 & -0.025 & -0.025 \\
\hline O10 & -0.731 & -0.731 & -0.731 & -0.731 & -0.731 & -0.731 & -0.731 & -0.731 \\
\hline H11 & 0.449 & 0.449 & 0.449 & 0.449 & 0.449 & 0.449 & 0.449 & 0.449 \\
\hline C12 & & -0.567 & -0.367 & -0.375 & -0.371 & -0.370 & -0.370 & -0.370 \\
\hline C13 & & & -0.572 & -0.360 & -0.377 & -0.373 & -0.373 & -0.372 \\
\hline C14 & & & & -0.568 & -0.366 & -0.373 & -0.370 & -0.368 \\
\hline C15 & & & & & -0.569 & -0.366 & -0.374 & -0.370 \\
\hline C16 & & & & & & -0.569 & -0.366 & -0.374 \\
\hline C17 & & & & & & & -0.569 & -0.366 \\
\hline $\mathrm{C} 18$ & & & & & & & & -0.568 \\
\hline
\end{tabular}


Table 2: Hydrogen bonds data of hydration shell for final solvated structure

\begin{tabular}{|c|c|c|}
\hline $\begin{array}{l}\text { Hydrophilic group - water } \\
\text { hydrogen bonds }\end{array}$ & $\begin{array}{l}\text { Mulliken charges on } \mathrm{H} \\
\text { and } \mathrm{O} \text { respectively }\end{array}$ & Distance $(\AA)$ \\
\hline $\mathrm{H} 11 \ldots . . \mathrm{O}(\mathrm{W} 1)$ & $0.443 /-0.854$ & 1.552 \\
\hline $\mathrm{O}(\mathrm{W} 3)-\mathrm{H} \ldots . . . \mathrm{O} 10$ & $0.466 /-0.836$ & 1.529 \\
\hline $\mathrm{O}(\mathrm{W} 4)-\mathrm{H} \ldots . . . \mathrm{O} 5$ & $0.421 /-0.513$ & 1.877 \\
\hline $\mathrm{O}(\mathrm{W} 12)-\mathrm{H} \ldots . . \mathrm{O} 5$ & $0.422 /-0.513$ & 1.946 \\
\hline $\mathrm{O}(\mathrm{W} 5)-\mathrm{H} \ldots . . . \mathrm{O} 6$ & $0.424 /-0.467$ & 1.901 \\
\hline $\mathrm{O}(\mathrm{W} 11)-\mathrm{H} \ldots \ldots \mathrm{O} 6$ & $0.397 /-0.467$ & 2.134 \\
\hline \multicolumn{3}{|l|}{$\begin{array}{c}\text { Water-water hydrogen } \\
\text { bonds }\end{array}$} \\
\hline $\mathrm{O}(\mathrm{W} 1)-\mathrm{H} . . . . \mathrm{O}(\mathrm{W} 4)$ & $0.430 /-0.837$ & 1.820 \\
\hline $\mathrm{O}(\mathrm{W} 1)-\mathrm{H} . . . . \mathrm{O}(\mathrm{W} 7)$ & $0.426 /-0.856$ & 1.710 \\
\hline $\mathrm{O}(\mathrm{W} 2)-\mathrm{H} \ldots . . . \mathrm{O}(\mathrm{W} 5)$ & $0.468 /-0.841$ & 1.568 \\
\hline $\mathrm{O}(\mathrm{W} 4)-\mathrm{H} \ldots \ldots \mathrm{O}(\mathrm{W} 12)$ & $0.437 /-0.801$ & 1.834 \\
\hline $\mathrm{O}(\mathrm{W} 5)-\mathrm{H} . . . . \mathrm{O}(\mathrm{W} 3)$ & $0.430 /-0.836$ & 1.723 \\
\hline $\mathrm{O}(\mathrm{W} 6)-\mathrm{H} \ldots . . . \mathrm{O}(\mathrm{W} 3)$ & $0.420 /-0.836$ & 1.777 \\
\hline $\mathrm{O}(\mathrm{W} 6)-\mathrm{H} . . . . \mathrm{O}(\mathrm{W} 11)$ & $0.458 /-0.832$ & 1.627 \\
\hline $\mathrm{O}(\mathrm{W} 7)-\mathrm{H} \ldots . . . \mathrm{O}(\mathrm{W} 6)$ & $0.476 /-0.867$ & 1.447 \\
\hline $\mathrm{O}(\mathrm{W} 8)-\mathrm{H} . . . . \mathrm{O}(\mathrm{W} 7)$ & $0.428 /-0.852$ & 1.700 \\
\hline $\mathrm{O}(\mathrm{W} 8)-\mathrm{H} . . . . \mathrm{O}(\mathrm{W} 4)$ & $0.418 / 0.837$ & 1.778 \\
\hline $\mathrm{O}(\mathrm{W} 9)-\mathrm{H} . . . . \mathrm{O}(\mathrm{W} 8)$ & $0.472 /-0.858$ & 1.537 \\
\hline $\mathrm{O}(\mathrm{W} 10)-\mathrm{H} . . . . \mathrm{O}(\mathrm{W} 2)$ & $0.445 /-0.840$ & 1.622 \\
\hline $\mathrm{O}(\mathrm{W} 11)-\mathrm{H} . . . . \mathrm{O}(\mathrm{W} 9)$ & $0.439 /-0.841$ & 1.635 \\
\hline
\end{tabular}

\subsection{Solvation}

The results indicate that the solvent environment has a significant effect on the dipole moment of the surfactant head group structure. The calculated dipole moment in aqueous solution is found to be $4.26 \mathrm{D}$ which is higher than in vacuo (3.36 D). This result shows that interactions with the aqueous phase influence the charge distribution in the system: water molecules induce an additional charge in the system. The dipole moment obtained for the solvated surfactant structure, which is bonded to the twelve water molecules (Table 3), is also higher compared to the result in vacuo. 
Table 3: Parameters of IMIDE head group hydration

$\mathrm{E}$ - total minimum energy of a system, D - binding energy, $\triangle \mathrm{ZPE}$ - zero point energy correction, ZPE corrected binding energy $D_{0}$, incremental binding energy $\Delta D_{0}$, dipole moment $\mu$ of hydrated complexes.

\begin{tabular}{|c|c|c|c|c|c|c|}
\hline $\begin{array}{l}\mathrm{N} \text { of water } \\
\text { molecules }\end{array}$ & $\begin{array}{c}\mathrm{E}, \\
\mathrm{kJ} / \mathrm{mol}\end{array}$ & $\begin{array}{c}\mathrm{D}, \\
\mathrm{kJ} / \mathrm{mol} \\
\end{array}$ & $\begin{array}{l}\triangle \mathrm{ZPE}, \\
\mathrm{kJ} / \mathrm{mol}\end{array}$ & $\begin{array}{c}\mathrm{D}_{0}, \\
\mathrm{~kJ} / \mathrm{mol}\end{array}$ & $\begin{array}{c}\Delta \mathrm{D}_{0}, \\
\mathrm{~kJ} / \mathrm{mol}\end{array}$ & $\begin{array}{c}\mu, \\
\text { Debye }\end{array}$ \\
\hline 0 & -1660404.577 & - & - & - & - & 3.4 \\
\hline 1 & -1861110.461 & 75.85 & 13.67 & 62.16 & - & 6.5 \\
\hline 2 & -2061782.101 & 117.45 & 21.79 & 95.66 & 33.48 & 4.4 \\
\hline 3 & -2262461.346 & 166.66 & 32.33 & 134.33 & 38.67 & 5.9 \\
\hline 4 & -2463172.600 & 247.88 & 44.39 & 203.49 & 69.15 & 6.5 \\
\hline 5 & -2663938.367 & 383.61 & 62.10 & 321.51 & 118.02 & 4.3 \\
\hline 6 & -2864634.741 & 449.94 & 76.16 & 373.78 & 52.27 & 5.7 \\
\hline 7 & -3065366.327 & 551.49 & 87.25 & 464.24 & 90.46 & 2.8 \\
\hline 8 & -3266066.497 & 621.63 & 104.84 & 516.78 & 52.54 & 1.0 \\
\hline 9 & -3466781.999 & 707.09 & 118.22 & 588.87 & 72.08 & 2.2 \\
\hline 10 & -3667498.024 & 793.08 & 130.17 & 662.90 & 74.03 & 2.8 \\
\hline 11 & -3868256.072 & 921.09 & 146.54 & 774.54 & 111.64 & 3.8 \\
\hline 12 & -4068940.277 & 975.26 & 158.07 & 817.18 & 42.63 & 4.8 \\
\hline
\end{tabular}

\subsection{Complex formation with water molecules}

The structure of the IMIDE head group bonded to twelve water molecules is presented in Figure 5. Water molecules were sequentially introduced around the head group and the resulting structure was optimized after each addition. The maximum number of water molecules that could be accommodated within hydrogen bonding limits, was twelve molecules. The head group with three carbon atoms attached was chosen for the building of the complex with water molecules. The reason for this is because no effect of additional carbons on the charge distribution in the head group was found (see section 3.2). It can be seen from Figure 5 that a structured pattern is formed from water molecules surrounding the surfactant head group. This interesting structure of hydration shell may have an effect on 
surfactant monolayer formation: it may lead to a highly ordered surfactant monolayer at the interface.

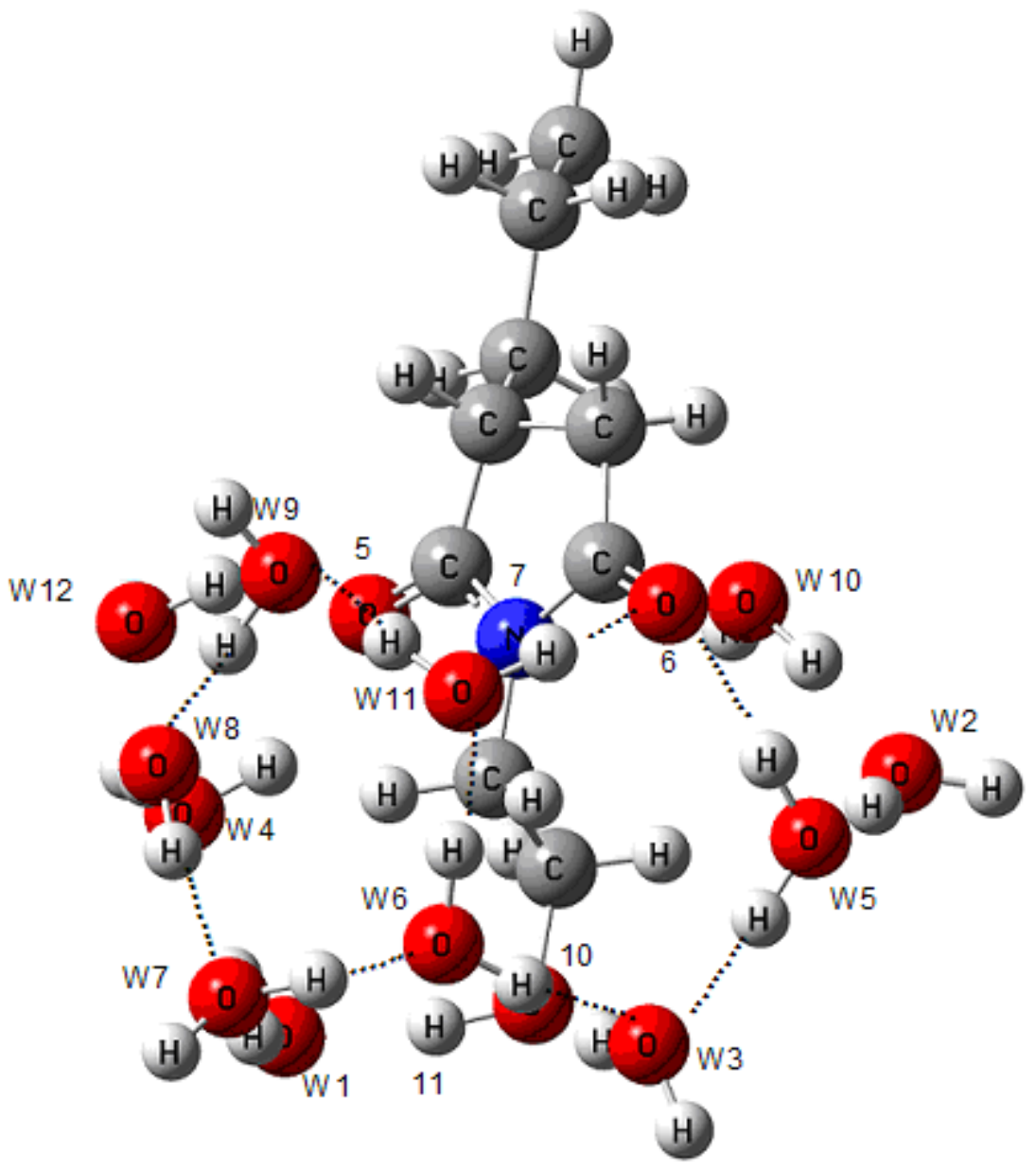

Figure 5 : Configurations of IMIDE head group with twelve water molecules

The hydrogen bond distances were measured and are summarized in Table 2 .

From the data in Table 2 it can be shown that all H-bonds can be divided into two groups: hydrophilic group-water hydrogen bonds (which are forming directly between water molecules and surfactant) and water-water hydrogen bonds (they are forming between water molecules). The hydrogen bond strengths vary from strong to medium $(1.529-2.134 \AA)$ with values typical for hydrogen bonds [20]. The strong binding site of the molecule is an alcohol group $(-\mathrm{OH})$ which provides the hydrogen bonds of the same strength (at around 
1.529-1.552 $\AA$ ) that is even stronger then could be formed between water molecules (1.537 $1.834 \AA$ ). The two amide carbonyl oxygen atoms in the IMIDE structure form the weakest hydrogen bonds $(1.877-2.134 \AA$ ) compared to any others hydrogen bonds due to the small charge present on the $\mathrm{O} 5$ and $\mathrm{O} 6$ atoms in the surfactant structure. The Mulliken charges on $\mathrm{H}$ and $\mathrm{O}$ atoms in the system are given in Table 2. The reason for the small charge on $\mathrm{O} 5$ and O6 is possibly the existence of electron resonance between the two carbonyl groups and nitrogen atom as the electron pair of nitrogen is delocalised over the two carbonyl groups in the succinimide structure. This resonance effect together with the high electronegativity of the $\mathrm{N}$ atom reduces the charge on the carbonyl oxygen atoms. It is shown in Figure 6.

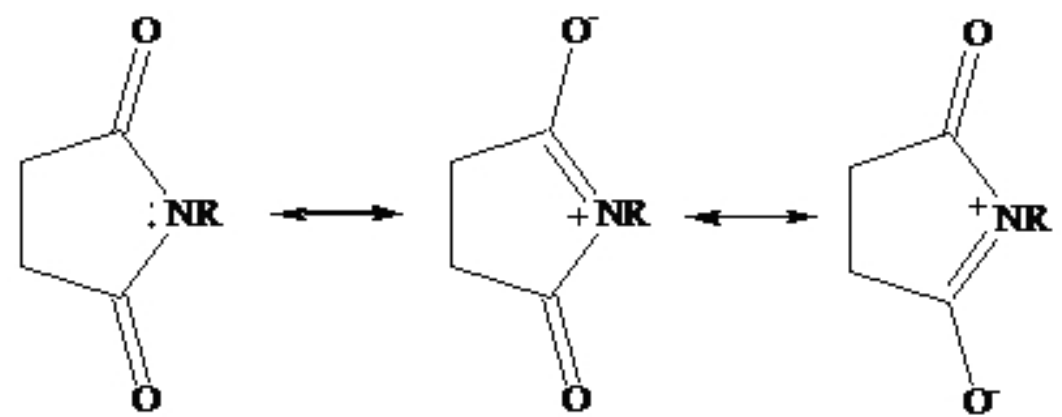

Figure 6 : The delocalization of nitrogen electron pair in succinimide molecule.

Thus the permanent charge is not present on these atoms.

Figure 7 illustrates the measured angles $\angle(\mathrm{C} 8-\mathrm{N} 7-\mathrm{C} 1)=\angle(\mathrm{C} 8-\mathrm{N} 7-\mathrm{C} 4)=123.31^{\circ}, \angle(\mathrm{C} 4-$ $\mathrm{N} 7-\mathrm{C} 1)=113.36^{\circ}$, indicative of a planar sp2 configuration for the $\mathrm{N}$ atom in a trigonal planar geometry.

Moreover, the nitrogen atom did not form hydrogen bonds with any water molecules. This is also due to electron pair delocalization. Based on the above discussion we can conclude that adsorption of the IMIDE surfactant on the water surface is mainly due to H-bonds formation between the oxygen atoms and water molecules, where the hydroxyl group in the hydrophilic part of the surfactant is the strongest anchor. 


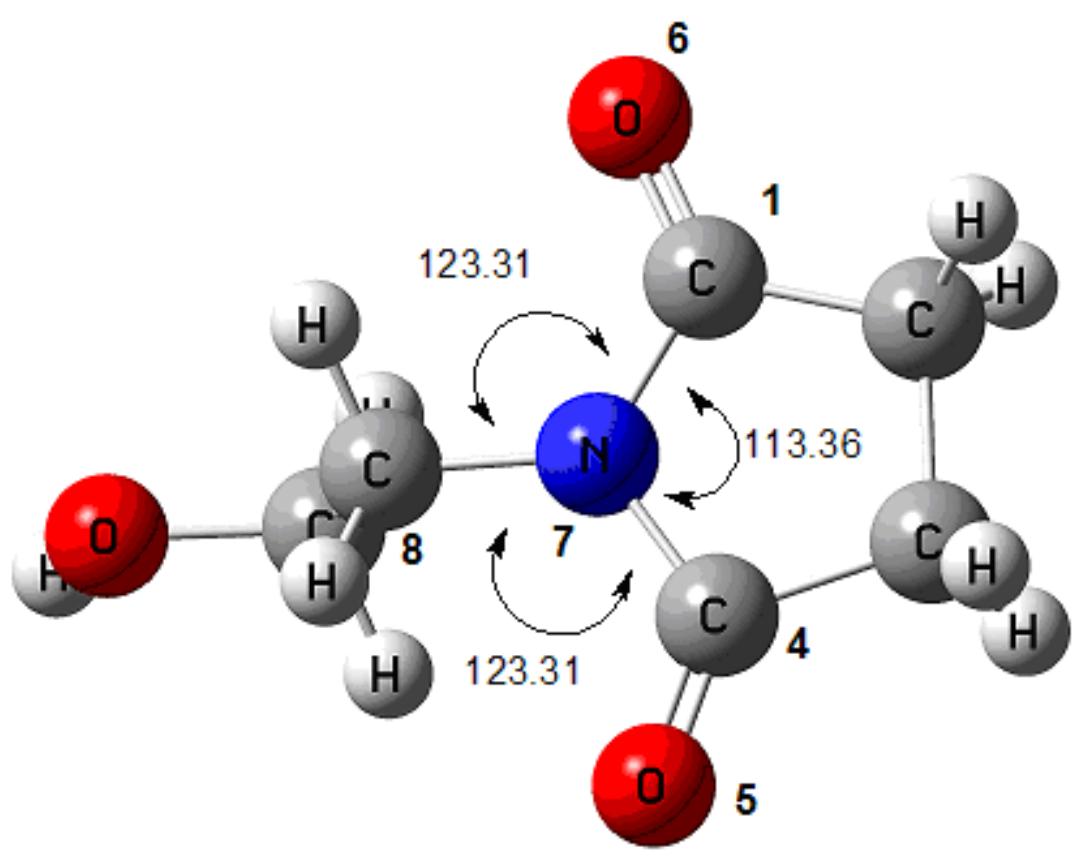

A

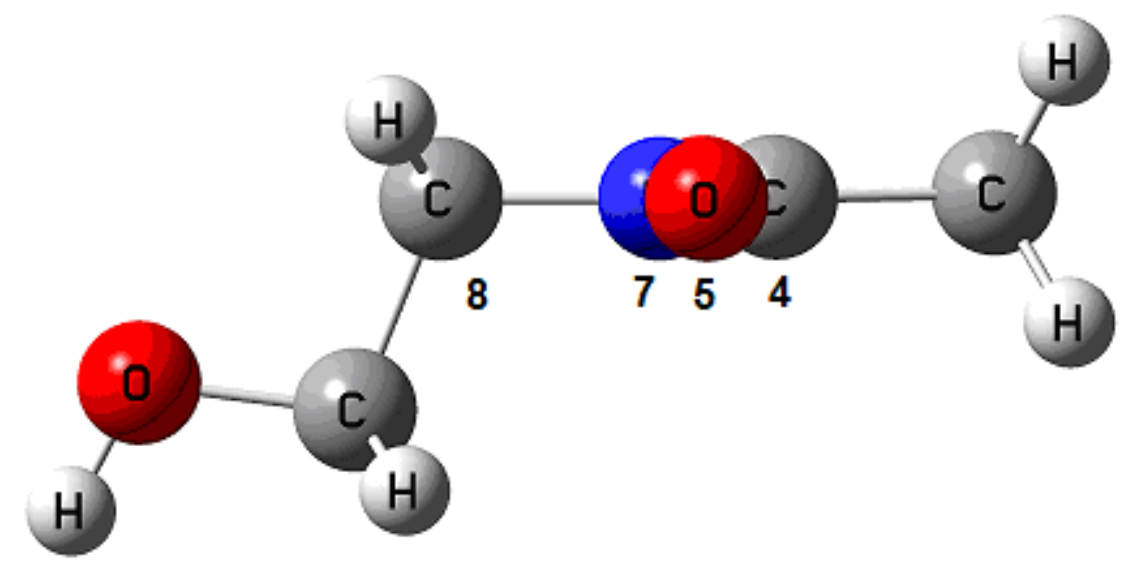

B

Figure 7: IMIDE head group structure: (a) Illustration of angles measured for the planar ring structure (top view); (b) Planar ring structure (side view)

\subsection{Binding energy of surfactant at the interface}

The stability of the hydration shell can be described with the ZPE-corrected binding energy $\left(D_{0}, \mathrm{~kJ} / \mathrm{mol}\right)$. The binding energy $\left(\mathrm{D}_{0}\right)$, total energy $(\mathrm{E})$ and dipole moments $(\mu)$ of the 
hydrated complexes with different number of water molecules are listed in Table 3 . The total energy (E) represents the minimum energy of the optimized structure.

It can be seen from Table 3 that the binding energy $\mathrm{D}_{0}$ increases, which indicates the stabilization of studied complexes and then the hydration shell becomes more stable as the number of water molecules increases. The incremental binding energy $\Delta D_{0}$ can be used to describe the effect of the each additional water molecule on the binding energy. The larger the value of $\Delta \mathrm{D}_{0}$ is, the stronger the effect on binding energy the water molecule has. Addition of a fifth and eleventh water molecule resulted in the largest change of the binding energy (Table 3) of the system compared to other water molecules. The comparison of these water molecules to the others showed that they form three hydrogen bonds when added to the system and complete the pattern of complexes by binding with the earlier added water molecules and therefore leading to the more stable intermediate complex structure.

No relationship between binding energy and dipole moment of the system was found in the present study. Since the dipole moment is the sum of vectors of individual bonds dipole moments it is not necessary that system with the higher dipole moment (higher polarity) will stronger interact with the water molecules.

\section{CONCLUSION}

The hydration shell of the IMIDE surfactant was firstly investigated at molecular level with the use of density functional theory. The results revealed that surfactant formed stable structure interacting with twelve water molecules. Binding energy of the system increases with increasing number of water molecules which indicates stabilization of the system due to interaction (hydrogen bonding) with the water molecules. The strongest anchor of the IMIDE surfactant at the interface is an alcohol group which was forming the strongest hydrogen bonds while carbonyl groups formed weak $\mathrm{H}$ bonds with the water molecules. No relation was found between dipole moment of a system and binding energy of surfactant at the interface. 


\section{ACKNOWLEDMENT}

The authors thank Lake International Technologies and African Explosives Limited for their financial support, for permission to publish the results and Prof. PH van Rooyen for his helpful discussions and providing an opportunity to use the computer lab to perform calculations presented in this article.

\section{REFERENCES}

[1] Tadros, T. F. (2005) Applied surfactants. Principles and applications. Verlag: Wiley-VCH.

[2] Hu. J., Zhang, X. and Wang, Z. (2010) A Review on progress in QSPR studies for surfactants. International Journal of Molecular Sciences, 11: 1020-1047.

[3] Villamagna, F., Whitehead, M. A. and Chattopadyay, A. K. (1995) A molecular modeling approach to the analysis of present and design of future surfactants for water-in-oil emulsions. Journal of Molecular Structure, 343: 77-103.

[4] I. Masalova., K. Kovalchuk and A. Ya. Malkin. (2010) IR studies of interfacial interaction of the succinic surfactant with different head groups in highly concentrated W/O emulsions. Paper accepted for publication in Journal of Dispersion Science and Technology.

[5] Tomlinson, A., Danks, T.N., Heyes, D.M., Taylor, S.E. \& Moreton, D.J. (1997) Interfacial characterization of succinimide surfactants. Langmuir, 13:5881-5893.

[6] Opawale, F. O. \& Burgess, D. J. (1997) Influence of interfacial properties of lipophilic surfactants on water-in-oil emulsion stability. $J$ of Colloid and Interface Science, 197: 142-150.

[7] Kovalchuk, K., Masalova, I. (2012) Factors influencing the crystallization of highly concentrated W/O emulsions. DSC study. South African Journal of Science, 108: $3 / 4$.

[8] Ganguly, S., Mohan, V.K., Bhasu, V.C.J., Mathews, E., Adiseshaiah, K.S. \& Kumar, A.S. (1992) Surfactant-electrolyte interactions in concentrated water-in-oil emulsions: FT-IR spectroscopic and low-temperature differential scanning calorimetric studies. Colloid and surfaces, 65:243-256. 
[9] Villamagna, F., Whitehead, M.A. \& Chattopadhyay, A.K. (1995) Mobility of surfactants at the water-in-oil emulsion interface. J. Dispersion science and Technology, 16:105-114.

[10] Dominguez, H. (2004) Computer simulation studies of surfactant monolayers mixtures at the water/oil interface: charge distribution effects. Journal of Colloid and Interface Science, 274: 665-672.

[11] Kovalchuk, K., Masalova, I. and Malkin, A. Ya. (2010) Influence of electrolyte on interfacial, rheological properties and shear stability of highly concentrated $\mathrm{W} / \mathrm{O}$ emulsions. Accepted for publication in Colloid Journal.

[12] Chen, M-L., Wang, Z-W. and Tao, F-M. (2009) DFT investigation of alkyl sulfate surfactant adsorption at the air-water interface. $J$ Dispersion Science and Technology, 30: 185-189.

[13] Zielinski, R. and Szymusiak, H. (2003) Structure of stable double-ionic model water clusters of quaternary alkylammonium surfactants with some monovalent counterions as derived by the DFT method. International Journal of Quantum Chemistry, 99: 724-734.

[14] Chen, M., Wang, Z., Wang, H., Zhang, G. and Tao, F. (2007) Investigation of adsorption of surfactant at the air-water interface with quantum chemistry method. Chinese Science Bulletin, 52: 1451-1455.

[15] Huibers, P. D. T. (1999) Quantum-chemical calculations of the charge distribution in ionic surfactants. Langmuir, 15: 7546-7550.

[16] Dominguez, H. (2002) Computer simulations of surfactant mixtures at the liquid/liquid interface. Journal of Physical Chemistry: 106: 5915-5924.

[17] Frisch, M. J. et al, Gaussian 03, Revision D. 01, Gaussian, Inc., Wallingford CT 2004.

[18] Ramachandran, K. I., Deepa, G. and Namboori, K. (2008) Computational Chemistry and Molecular Modeling. Principles and applications. Berlin: Springer.

[19] Gece, G. (2008) The use of quantum chemical methods in corrosion inhibitors studies. Corrosion Science, 50: 2981-2992. 
[20] Kysel, O., Budzak, S., Medved, M and Mach, P. (2008) MP2, DFT-D, and PCM study of the HMB-TCNE complex: Thermodynamics, electric properties, and solvent effects. International Journal of Quantum Chemistry, 108: 1533-1545.

[21] Mammino, L. and Kabanda, M. M. (2010) A computational study of the carboxylic acid of phloroglucinol in vacuo and in water solution. International Journal of Quantum Chemistry, 110: 595-623.

[22] Tomasi, J. and Persico, M. (1994) Molecular Interactions in solution: An overview of methods based on continuous distributions of the solvent. Chemical review, 94: 2027-2094. 